\title{
Serine/Threonine-Protein Kinase WNK2
}

National Cancer Institute

\section{Source}

National Cancer Institute. Serine/Threonine-Protein Kinase WNK2. NCI Thesaurus. Code C143108.

Serine/threonine-protein kinase WNK2 (2297 aa, $243 \mathrm{kDa}$ ) is encoded by the human WNK2 gene. This protein plays a role in the regulation of cell signaling and ion transport. 